This item was submitted to Loughborough's Research Repository by the author.

Items in Figshare are protected by copyright, with all rights reserved, unless otherwise indicated.

\title{
Self-management of health-behaviors among older and younger workers
} with chronic illness

PLEASE CITE THE PUBLISHED VERSION

http://dx.doi.org/10.1016/j.pec.2009.02.014

PUBLISHER

(C) Elsevier Ireland Ltd.

VERSION

AM (Accepted Manuscript)

LICENCE

CC BY-NC-ND 4.0

\section{REPOSITORY RECORD}

Munir, Fehmidah, Hafiz T.A. Khan, Joanna Yarker, Cheryl Haslam, Helen Long, Manpreet Bains, and Katryna Kalawsky. 2019. "Self-management of Health-behaviors Among Older and Younger Workers with Chronic Illness”. figshare. https://hdl.handle.net/2134/10434. 
This item was submitted to Loughborough's Institutional Repository (https://dspace.lboro.ac.uk/) by the author and is made available under the following Creative Commons Licence conditions.

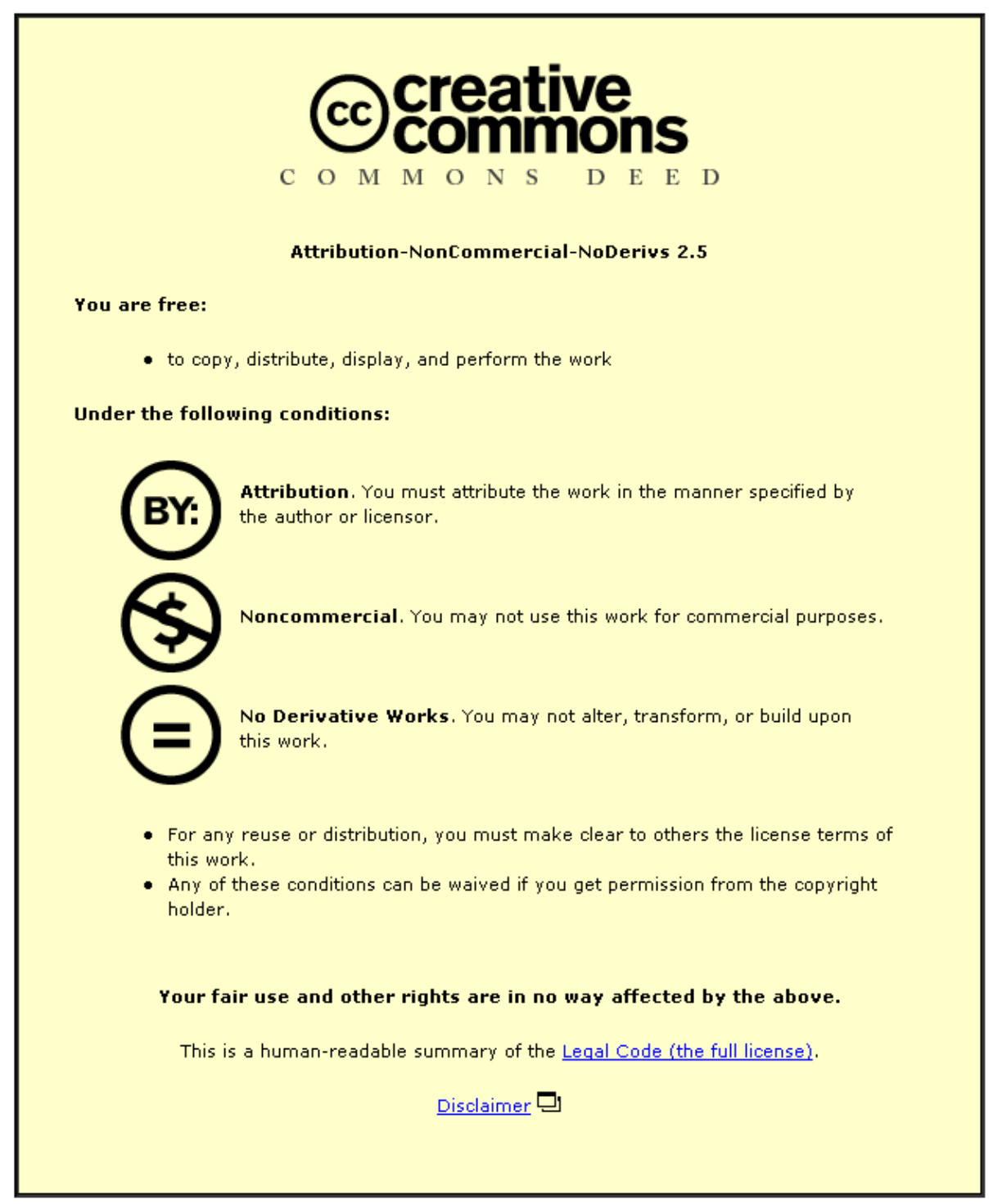

For the full text of this licence, please go to: http://creativecommons.org/licenses/by-nc-nd/2.5/ 


\title{
HEALTH-BEHAVIORS AMONG OLDER AND YOUNGER WORKERS WITH CHRONIC ILLNESS
}

PUBLISHED IN: Patient Education and Counselling, 2009, 77: 109-115

\author{
${ }^{\mathrm{a}}$ Fehmidah Munir, ${ }^{\mathrm{b}}$ Hafiz T.A. Khan, ${ }^{\mathrm{c} J o a n n a}$ Yarker, ${ }^{\mathrm{a}}$ Cheryl Haslam, ${ }^{\mathrm{d}}$ Helen Long \\ ${ }^{\mathrm{a}}$ Manpreet Bains, ${ }^{\mathrm{a}}$ Katryna Kalawsky
}

${ }^{\mathrm{a}}$ Department of Human Sciences, Brockington Building, Loughborough University, Loughborough, Leicestershire LE11 3TU, UK.

${ }^{\mathrm{b}}$ Oxford Institute of Ageing, University of Oxford, UK

${ }^{\mathrm{c}}$ Goldsmiths College, University of London, UK

${ }^{\mathrm{d}}$ Department of Work and Pensions, Sheffield, UK

Running Title: health behaviours by older and younger workers

Corresponding author (and reprints): Dr Fehmidah Munir, Department of Human

Sciences, Brockington Building, Loughborough University, Loughborough,

Leicestershire, LE11 3TU, UK.

Email: f.munir@lboro.ac.uk

Telephone: +44(0)1509228228 


\section{ABSTRACT}

Objectives: To examine health behaviors carried out by older (aged 50-69 years) and younger workers (aged 20-49 years) with a chronic illness.

Methods: Questionnaire data was collected from 759 employees with a diagnosed chronic illness. Four categories of self-managing health behaviors were examined: using prescribed medication, monitoring and responding to symptoms, managing an appropriate diet and exercising.

Results: The majority of participants (56-97\%) reported being advised to carry out health behaviors at home and at work. Controlling for confounding factors, medication use was associated with younger and older workers. Managing an appropriate diet was associated with younger workers with asthma, musculoskeletal pain or diabetes. Exercising was associated with younger workers with asthma and with older workers with heart disease, arthritis and rheumatism or diabetes.

Conclusions: The findings indicate that there are differences in diet and exercise activities among younger and older workers managing the same chronic illness. Practice implications: To increase health behaviors at work, improved communication and understanding between the different health professions and the patient/employee is required so that different tailored approaches can be effectively targeted both by age and within the context of the working environment, to those managing asthma, heart disease, diabetes and arthritis and rheumatism.

Keywords: Chronic disease, older workers, health behaviors, exercise, physical activity, diet, symptom management. 


\section{Introduction}

As the proportion of workers aged 50 and above is growing steadily and the number of younger workers entering the workforce is slowing in comparison, keeping people at work for longer is a key Government strategy for a number of industrialised countries [e.g. 1]. Since increasing age is a risk factor for many illnesses, particularly chronic illnesses, the health and well-being of the working population is therefore of fundamental importance. Not surprisingly then, from a public health perspective, efforts are being made to help individuals remain active and healthy by engaging in health-sustaining activities so that they can continue working for longer, retire later and remain active after retirement.

Taking into account the health demographics of older workers and the Government strategy to promote longer healthy working lives, the problem becomes how to increase health-sustaining activities in the workplace for those workers already burdened by a chronic illness. Chronic illnesses such as coronary heart disease, hypertension, arthritis, diabetes, and musculoskeletal pain are reported to be more prevalent in those aged 55-64 years old [2,3]. In contrast, asthma is more prevalent in those aged below 45 years and stress, depression and anxiety is reported as prevalent in young-to-middle aged groups (aged 35-54 years) [2, 3]. These chronic illnesses are prevalent in the working population and associated with high sickness absence [4], early retirement and poor health outcomes [4, 5]. To meet government targets for improving the health and well-being of people and the demands of an ageing workforce, it is essential to better understand the needs of employees with chronic illness: i.e. how their illness affects their ability to work; how they manage 
their illness at work and importantly whether these needs change as the employee grows older.

Encouraging and supporting patients with a chronic illness to carry out health behaviours such as prescribed medication adherence, following an appropriate diet plan and exercising have proven to be beneficial in reducing illness symptoms and improving health and well-being [6]. However, studies on health behaviours have reported mixed findings for younger and older adults with chronic illness. Some studies report lower adherence to medication and other self-management behaviours in older adults compared with younger adults with type 2 diabetes, hypertension, arthritis or mental health problems [7-10], while other studies report younger adults experience more difficulty in managing medication and illnesses such as asthma and diabetes compared with older adults [11-13]. Exercise has been associated with both younger age $[14,15]$, and with older adults, both healthy or with a chronic illness $[12$, $16,17]$. In terms of health behaviors among workers, most studies have examined correlates of physical activity and dietary patterns [18-20] or outcomes of these behaviors in worksite health promotion programs [21,22]. There are only few comparable studies on younger and older workers. A study on dietary behaviors in the workplace found that older male workers were more likely to consume poultry, fish and low fat milk than younger male workers and interest in dietary change was evident in male workers aged in their thirties [23]. Studies on physical activity show that older workers are more likely to engage in leisure-time physical activity [24, 25]. There is relatively little research comparing self-managing health behaviors of older and younger workers across different chronic illnesses. 
In the present study, we examined four self-managing health behaviours typically required to be carried out by patients as advised by their physician: using prescribed medication; monitoring and responding to symptoms; managing an appropriate diet; and exercising [6]. These behaviors were examined among older workers (aged 5069 years) and younger workers (aged 20-49 years) managing one of the following chronic illnesses: heart disease, musculoskeletal pain, asthma, depression and anxiety, diabetes, arthritis and rheumatism.

\section{Methods}

\subsection{Sample}

The survey, carried out between April and September 2004, was cross-sectional and based on participants recruited from four organisations across three sectors: local government, transport and manufacturing (two companies; referred to as organisations A and B). To ensure anonymity, workers were sent a questionnaire through their occupational health departments. The number of questionnaires sent varied according to organisational size. All workers in the two manufacturing companies were sent a questionnaire (employing 3,600 and 5,600 workers), and a random sample of 1:3 workers in the local government (employing 14,000 workers) and 1:2 workers in the transport organisation (employing 12,000 workers) were sent questionnaires $(26,200$ questionnaires were sent in total across the four organisations). Completed questionnaires were mailed directly to the research team. To monitor overall response rates, the questionnaire asked all workers, independent of their health status for demographic and job-related details. Workers managing a chronic illness were asked additional questions about their health and work. A $28 \%$ response rate (response rates 
ranged from $26 \%$ to $30 \%)$ was achieved for returned questionnaires $(N=7,336)$, of which $21 \%(N=5,264)$ were completed questionnaires. While this is a below average response rate for mailed surveys [26,27], this is not unusual for organisational-based questionnaires outside of annual employee surveys which are typically in the region of $27-31 \%$ due to survey fatigue [28]. The low response rate in this study may also be expected given the study's focus on chronic illness, which may have seemed irrelevant to many workers.

Respondents were asked in the questionnaire to self-report on any medically diagnosed chronic illness they currently experienced (and had received medical treatment for), and to indicate which primary condition (if more than one was listed) most affected their work. This measure was developed to be consistent with other self-report measures of chronic illness [29-32]. Twenty-seven per cent (1,474 respondents) reported at least one chronic illness. A total of 17 different groups of chronic diseases were classified from the sample using the International Classification of Diseases [33] and are reported elsewhere [34]. For the purpose of this study, six of these groups were chosen for analysis: musculoskeletal pain $(n=226$; those reporting pain anywhere along the musculoskeletal system: back, shoulders, neck, arms, elbows, wrist and lower limbs), arthritis and rheumatism $(\mathrm{n}=130)$, asthma $(\mathrm{n}=126)$, depression and anxiety $(n=118$; those reporting either depression, anxiety or a combination of both), heart disease $(n=79$; those reporting myocardial infarction, angina, heart failure, stroke and hypertension [39\% of heart disease sample]) and diabetes $(n=80 ; 74 \%$ reporting diabetes II) resulting in total of 759 participants. Participants age ranged from 20-69 years $($ mean $=46.82$ years, SD 9.10). 
These chronic illness groups were chosen for several reasons. First, these illnesses are the most prevalent reported at work in this sample and in national Government surveys [e.g. 35] which are also based on self-report data. They are also to a great extent self-managed diseases in that such individuals need to perform various healthsustaining activities by themselves [e.g. 36, 37]. These activities include selfmonitoring of symptoms; proper use of medication; appropriate eating plan and regular exercise. Respondents in each of the six chronic illness groups were only selected if they had been medically diagnosed by their physician (for which they had received or are receiving treatment for); had a minimum disease duration of one year (3 months for participants with musculoskeletal pain or heart disease); if they did not present co-morbidity relating to one of the other diseases in the present study; if they were required to carry out self-managing health behaviors at work by their physician; and if they reported their age.

\subsection{Measures}

Self-managing health behaviors carried out in the workplace were measured using a modified version of the illness symptoms Self-Management Behaviors Scale [38, 39]. Based on the scale developed by Lorig et al [38] and Clark and Dodge [39], respondents were asked to rate how closely they were following the advice of their physician in carrying out various self-management activities specific to their chronic disease whilst at work. This was measured by seven items which asked participants to rate how closely they were following the advice in taking prescribed medication (1 item), managing the symptoms of their illness as advised by their physician (4 items; monitor and respond to fatigue, pain and other symptoms, carry out other activities 
beside medication to reduce symptoms), exercising whilst at work (e.g. during breaks and lunch hour; 1 item) and following an appropriate diet plan (1 item). All responses were measured on a 10 point Likert scale $(1=$ following advice not closely at all; to $10=$ very closely). As participants carry out health behaviours outside the workplace too (i.e. at home), they were asked to rate the same questions again for behaviours carried out at home. For both home and work behaviours, if a participant was not advised on a particular behaviour, a 'not applicable' response was available for each health behaviour question.

Demographic data were collected from all respondents, on age (in years), gender $(0=$ male, $1=$ female) and tenure (length of employment in years) and occupational group was recorded according to the National Statistics Socio-economic Classification of eight-digit occupational titles for England and Wales. These were grouped into nonmanual jobs (higher managerial and professional, lower managerial and professional, and intermediate) and manual jobs (lower supervisory and technical, semi routine and routine occupations).

Respondents reporting a chronic disease were asked to self-report how long they had managed their illness (time since diagnosis in months or years) and about their current severity of illness symptoms related to their reported illness (measured on a 3 point Likert scale from mild to severe). Height and body weight were recorded, and a body mass index $\left(\mathrm{kg} / \mathrm{m}^{2}\right)$ of 25 to 30 was defined as overweight, and $>30$ was defined as obese.

\subsection{Analyses}


Age distribution were initially examined by chronic illness and banded into three age groups 20-34 $(\mathrm{N}=89), 35-49(\mathrm{~N}=355)$ and 50-69 $(\mathrm{N}=315)$. As the observed frequencies for heart disease, diabetes and arthritis were relatively small for the younger age group 20-34 years (Table 1), to increase statistical power, this group was combined with 35-49 age group, resulting in a final banding of two age groups: 20-49 $(\mathrm{N}=444), 50-69(\mathrm{~N}=315)$.

Chi-square tests were conducted to compare characteristics between the two age groups and unpaired t-test were conducted to compare between the age groups on mean health behavior scores. Linear regression analyses were performed to estimate the relationship of health behaviors for younger and older workers managing a specific chronic illness. Adjustments were made for potential confounding variables of time since diagnosis, illness severity, gender, socio-economic status and organization type. Body mass index was additionally controlled for in the analyses for diet and exercise behaviors.

\section{Results}

As the response rate was lower than anticipated, we conducted statistical analyses to identify potential response biases between responders and non-responders by comparing the demographic profile of both groups. The demographic profile data of non-responders was obtained from each organisation's Human Resources (data not shown). For each organisation, t-tests between the two groups revealed no significant differences in age, gender or occupational status (all $p>.05$ ). Comparing each illness group with non-responders, participants with chronic illnesses did not significantly differ from their respective colleagues in terms of gender and occupational status (all 
$p>.05)$. However, those reporting heart disease and arthritis and rheumatism were significantly older than non-responders $(p<.05)$. Across organisations, musculoskeletal pain was the most reported condition. For administration and manufacturing A organisations, arthritis and rheumatism was the second most prevalent condition. For transport and manufacturing B, asthma was the second most reported condition (data not shown).

Across the three age groups, musculoskeletal pain was the most reported condition (Table 1). Chi-square comparison between the three age groups are presented in Table 1. Musculoskeletal pain, depression and anxiety and asthma were significantly more prevalent in the 20-49 age group compared with the other two age groups. Heart disease, arthritis and diabetes were more prevalent in the 50-69 age group. Comparisons between gender on chronic illness found arthritis and rheumatism more prevalent in women and heart disease and diabetes more prevalent in men. Overall, fifty-two percent reported their chronic disease to be mild and $31 \%$ reported it as moderate $(p<.001)$ (data not shown). Chi-square analyses for each illness group showed workers were more likely to report their chronic illness to be mild if they had asthma, heart disease, or diabetes ( $p<.001$, in all cases). Older workers with musculoskeletal pain were more likely to report their condition as being severe $(p<.001)$ (data not shown). Across the sample, $52 \%$ were obese and $27 \%$ were overweight $(p<.01)$. Correlation analyses showed no association between obesity and age. Chi-square analyses for each illness group showed obesity to be prevalent in those with asthma $(p<.05)$ and among those with either heart disease or diabetes in manual jobs $(p<.01)$ (data not shown). 
Table 2 shows the percentage of participants advised to carry out health behaviours at home and at work a by their physician (irrespective of compliance). The majority of participants reported being advised to carry out health behaviours both at home and at work. Table 3 shows the mean difference in carrying out a particular health behaviour by younger and older workers. Older workers showed significantly higher mean scores for all four self-managing health behaviours. Results for the linear regression analyses are shown in Table 4. After adjustment for organization type, tenure, occupation, gender, and time since diagnosis, prescribed medication use at work was significantly associated with both younger and older workers with heart disease, asthma, and diabetes, but negatively associated with both younger and older workers with musculoskeletal pain. Managing an appropriate diet at work was only associated with younger workers with asthma, musculoskeletal pain or diabetes, even after additionally adjusting for BMI. Managing symptoms at work was only associated with older workers with asthma. Exercising was associated with younger workers with asthma, and with older workers with heart disease, arthritis and rheumatism or diabetes, even after additionally adjusting for BMI. In contrast, exercising was negatively associated with older workers reporting depression and anxiety.

\section{Discussion and conclusion}

\subsection{Discussion}


The main goal of this study was to explore the health behaviours carried out by younger and older workers managing a chronic illness in the workplace. The health behaviours examined were those which workers were asked to carry out by their physicians: using prescribed medication, monitoring and responding to symptoms, managing an appropriate diet and exercising. In the present study, older workers (aged 50-69 years) had higher mean scores in carrying out self-managing health behaviours related to their chronic illness, compared to their younger counterparts (aged 20-49 years). These findings suggest a healthy worker effect: older adults are more likely to be working if their illnesses are mild to moderate or under control through good self-management. Those with poor self-management or severe illnesses are most likely to have taken early ill-health retirement [40]. This may further explain the difference in level of compliance between the younger and older workers. Younger workers reporting lower compliance may end up taking early ill-health retirement as they age, and only those with good health-management adherence are likely to remain in employment as older workers. Longitudinal research is necessary to determine this potential development.

With regard to self-managing behaviours across the different chronic illnesses by age, after controlling for individual-level (gender, time since diagnosis, severity of illness and BMI index) and organisational-level (tenure, occupation and organization type) confounders, differences in self-managing behaviours between the two age groups emerged. Overall, younger workers preferred self-managing behaviours that involved managing an appropriate diet and older workers preferred exercise. Furthermore, these different self-managing behaviours were adopted by the two different age groups managing the same chronic illness. For example, older workers with diabetes 
were more likely to actively manage their diabetes with exercise whereas younger workers with diabetes were more likely to manage theirs through diet. There are a number of potential explanations for the different use of self-managing behaviour strategies. Younger workers may generally be more health-conscious with what they eat, or finding it easier to follow an appropriate diet plan at work, whereas older workers may find it more difficult to choose food with the right nutritional value. It might be that older workers carry out exercise during work and younger workers exercise after working hours. As diet was associated with musculoskeletal pain for younger workers, it is possible that younger workers are more aware of the types of food and supplements that can help increase bone density and functional ability [4145]. An appropriate diet can also help with weight loss and therefore help reduce back pain [45]. As $79 \%$ of the sample in this study were overweight or obese, it is possible that younger workers with musculoskeletal pain received advice on diet. Further research is required to corroborate these potential explanations.

The differences in dietary and exercise behavior between the age groups can partially be explained by examining age-related research on exercise behavior. It is possible that older workers make a personal self-assessment to how useful and effective a particular health behavior will be to improving the status of their chronic illness in relation to their overall functional capacity and work ability. In other words, it's the effect of the chronic illness on their physical ability rather than the chronic illness itself that may motivate older workers to follow the advice of their physician on exercising. These findings corroborate the activity theory of ageing [e.g. 46] and studies on motivational factors for exercising that report older adults placed more importance on exercising if they felt it would improve their physical functional ability 
- such as strength, postural stability and flexibility - than on preventing illnesses per se [47]. This may explain the negative relationship between older workers with depression and anxiety and exercising, as depression and anxiety are perhaps perceived by workers to affect mood and cognition more than physical functional ability. In addition, those with depression may not exercise due to symptoms of fatigue associated with depression, may have withdrawn from exercise due to their illness, or may not have been recommended exercise by their health professional. However, recent research suggests an important relationship between depression and physical activity, whereby moderate levels of physical activity have been shown to improve depression [48-50], anxiety [50, 51] and general psychological well-being [50]. Exercise has also been shown to improve aspects of mental functioning such as planning, short-term memory and decision making [51]. Therefore, encouraging workers with depression and anxiety to engage in physical activity is likely to have large potential benefits.

Both younger and older workers used prescribed medication at work for managing heart disease, asthma and diabetes. These findings contradict the general literature in that adherence to medication is on average quite poor particularly among older adults [11]. Again this finding is unsurprising due to our expectations of the healthy worker effect. Those with musculoskeletal pain were less likely to use medication at work. There may be certain factors associated with musculoskeletal pain not measured in this study, that may help to explain the low use of medication by these groups. For example, most types of musculoskeletal pain are mild and largely episodic, therefore not requiring prescribed medication. In addition, treatment and management of musculoskeletal pain symptoms commonly involve therapeutic strategies such as 
physiotherapy and massages which are perceived to be more beneficial than medication [52].

Except for older workers with asthma, neither age groups were likely to monitor and respond to symptoms at work related to chronic illness. This may be due to workplaces not being conducive to employees managing illnesses. There may be little flexibility for employees to take a few minutes to monitor their symptoms or to even be made aware of how work demands are affecting their illness. Furthermore, evidence suggests few organisations have comprehensive policies and co-ordinated systems aimed at providing health-related support and workplace adjustments [53], and employees may therefore feel deterred or prevented from carrying out selfmanaging behaviors. Finally, some employees may not self-manage their illness at work in fear of drawing attention to themselves and their illness due to feeling stigmatised by their illness or that their professional integrity is at risk [32]. On the other hand, it is plausible that many employees check and respond to their symptoms outside of working hours which may be sufficient. Older people may be more inclined to monitor and respond to their asthma symptoms despite any potential barriers perhaps because they are more susceptible to such symptoms which may be more pronounced due to age-related decline in lung function capacity [54]. Further research is needed here to delineate the age-related behavior in managing asthma at work, and the potential workplace barriers, perceptions and compliance toward selfmanaging chronic illness at work.

A limitation of the study is the low response rate as it may represent a potential source of response bias. However, statistical analyses using organisational data of non- 
responders showed no significant differences in participation by gender, age and occupational status indicating that the sample is representative of the population studied. In addition, the response rate is adequate for a survey of this nature [28]. A number of explanations may account for the low response rates in this study. First discussions with participating organisations confirmed observations of survey fatigue. This is an increasing problem faced by researchers conducting organisational based research, despite usage of response-inducing techniques [28]. Second, the study relied on self-report data in identifying those with chronic illnesses, which may have resulted in under-reporting of chronic illnesses, leading to a somewhat lower response rate. Third, those with a chronic illness may have felt uncomfortable in completing the questionnaire, or felt their illness posed no problem at work or simply chose not to fill it in due to lack of time.

\subsection{Conclusion}

The findings from this study indicate that there are differences in diet and exercise activities among younger and older workers managing the same chronic illness. Further longitudinal research is required to understand what factors encourage or deter self-managment of chronic illness at work in the different age groups. Such studies can capture information on compliance, changes in self-managing behaviors, employment status and the fluctuations in physical, social and psychological correlates. Such information can help occupational health professionals design, implement and evaluate appropriate intervention strategies in encouraging selfmanagement of illness, to help promote such employees' well-being and minimise subsequent age-related decline in health and well-being. 


\subsection{Practice implications}

There are a number of health promotion implications regarding our findings. The workplace is an ideal environment in which to influence and educate individuals on the benefits illness self-management can accrue. There is the need to develop a more integrated multidisciplinary approach between health professionals and occupational health in managing and delivering health education and health promotion to patients who are in employment. To increase health behaviors at work, improved communication and understanding between the different health professions and the patient/employee is required so that different tailored approaches can be more effectively targeted both by age and within the context of the working environment, to those managing asthma, heart disease, diabetes and arthritis and rheumatism. For example, any strategy for increasing self-managing health behaviors at the workplace should include the utilisation of psychological processes to increase motivation and shape intentions and behaviors. Overall, occupational health services can help create a workplace culture that places a high value on health, educating both younger and older workers on the value of looking after their health and the benefits of following advice given by healthcare professionals. 


\section{Acknowledgements}

This work was supported by a grant from the European Social Fund and undertaken while the authors were employed at the University of Nottingham. The contributions of Amanda Griffiths, Sara Cox and Stavroula Leka to the early planning of the research are acknowledged. We thank participating organisations for access to their workplaces and employees. Ethical Approval was granted by the University of Nottingham Ethics Committee

The authors confirm all personal identifiers have been removed or disguised so that the participants described are not identifiable and cannot be identified through the details of the story. 


\section{REFERENCES}

[1] HM Government. Opportunity age: meeting the challenges of ageing in the $21^{\text {st }}$ century. London: The Stationary Office; 2005: 17-19.

[2] Office for National Statistics. Census 2001. Office for National Statistics, UK. 2001.

[3] Health \& Safety Executive. Self-reported work-related illness and workplace injuries 2006/2007. Sudbury, Suffolk: HSE Books, 2008.

[4] Henderson M, Glozier N, Elliot, KH. Long term sickness absence. Br Med J. 2005; 330: 802-803.

[5] Lewin R. Return to work after MI, the roles of depression, health beliefs and rehabilitation. Int J Cardiol. 1999; 72: 49-51.

[6] Clark NM, Becker MH, Janz NK, Lorig K, Rakowski W, Anderson L. Selfmanagement of chronic disease by older adults. J Aging Health.1991; 3: 3-27.

[7] Morrell RW, Park DC, Kidder DP, Martin M. Adherence to antihypertensive medications across the life span. Gerontologist. 1997; 37: 609-619. 
[8] Gucciardi E, DeMelo M, Offenheim A, Steward DE. Factors contributing to attrition behaviour in diabetes self-management programs: A mixed method approach. BMC Health Serv Res. 2008; 8: 33-37.

[9] Wetherell JL, Kaplan RM, Kallenberg G, Dresselhaus TR, Sieber WJ, Lang AJ. Mental health treatment preferences of older and younger primary care patients. Int J Psych Med. 2004; 34: 219-233.

[10] Elliot RA. Poor adherence to medication in adults with rheumatoid arthritis reasons and solutions. Dis Manage Health Outcomes. 2008; 16: 13-29.

[11] Diette GB, Krishnan JA, Dominici F, Haponik E, Skinner EA, Steinwaschs D, Wu AW. Asthma in older patients - factors associated with hospitalization. Arch Int Med. 2002; 162: 1123-1132.

[12] Gignac M, Davis AM, Hawker G, et al. "What do you expect? You're just getting older": A comparison of perceived osteoarthritis-related and agingrelated health experiences in middle- and older-age adults. Arthritis Rheum. 2006; 55: 905-12.

[13] Walker E, Molitch M, Kramer MK, Kahn S, Ma Y, Edelstein S, Smith K, Johnson MK, Kitabchi A, Crandall J. Adherence to preventive medications predictors and outcomes in the diabetes prevention program. Diab Care. 2006; 29: 1997-2002. 
[14] Stephens T, Caspersen CJ. The demography of physical activity. In: Bouchard C, Shepard RJ, Stephens T, eds. Physical activity, fitness and health. Champaign IL: Human Kinetics; 1994: 204-13.

[15] MacAuley D, McCrum EE, Stott G, et al. The Northern Ireland Health and Activity Survey. Belfast: The Stationary Office; 1994.

[16] Brownson RC, Jones DA, Pratt M, Blanton C, Heath GW. Measuring physical activity with the behavioural risk factor surveillance system. Med Sci Sports Exerc. 2000; 32: 1913-18.

[17] Costa DL. Causes of improving health and longevity at older ages: A review of the explanations. Genus, 2005; 61: 21-38.

[18] Schmitz K, French SA, Jeffery RW. Correlates of changes in leisure time physical activity over two years: The health worker project. Prev Med. 1997; 570-79.

[19] Popham F, Mitchell R. Leisure time exercise and personal circumstances in the working population: longitudinal analysis of the British household panel survey. J Epidemiol Community Health. 2006; 270-74.

[20] McNaughton SA, Mishra GD, Brunner EJ. Dietary patterns, insulin resistance and incidence of type 2 diabetes in the Whitehall II study. Diabetes Care. 2008; 1343-48. 
[21] Engbers LH, van Poppel MN, Paw MJ, van Mechelen W. Worksite health promotion programs with environmental changes: a systematic review. Am J Prev Med. 2005; 61-70.

[22] Goetzel RZ, Ozminkowski RJ. The health and costs benefits of work site health promotion programs. Annu Rev Public Health. 2008; 303-23.

[23] Fleming S, Keller C, OConnor M. Eating patterns and factors influencing likely change in the workplace in Ireland. Health Promot Int. 1997; 187-96.

[24] Fleming LE, Lee DJ, Martinez AJC, et al. The health behaviors of the older US worker. Am J Ind Med. 2007; 50: 427-37

[25] Seitsamo J, Tuomi K, Martikainen R. Activity, functional capacity and wellbeing in ageing Finnish workers. Occup Med. 2007; 57: 85-91.

[26] Baruch Y: Response rate in academic studies - a comparative analysis. Hum Rel. 1999; 52: 345-53.

[27] Roth PL, BeVier CA: Response rates in HRM/OB survey research: Norms and correlates, 1990-1994. J Manage. 1998; 24: 97-117. 
[28] Ibeh K, Brock JK-U, Zhou YJ: The drop and collect survey among industrial populations: theory and empirical evidence. Ind Market Manage. 2004; 33: $155-65$.

[29] Idler, E.L., Hudson, S.V., \& Leventhal, H. (1999). The meanings of selfratings of health. Research on Aging, 21, 458-76.

[30] Dewa CS, Lin E: Chronic physical illness, psychiatric disorder and disability in the workplace. Soc Sci Med. 2000; 51: 41-50.

[31] Lerner D, Amick BC, Malspeis S, Rogers WH. A national survey of healthrelated work limitations among employed persons in the United States. Disabil Rehab. 2000; 22: 225-32.

[32] Munir F, Leka S, Griffiths A: Dealing with self-management of chronic illness at work: predictors for self-disclosure. Soc Sci Med. 2005; 60: 1397-1407.

[33] World Health Organization. International Classification of Diseases - Version 10. Geneva: World Health Organization.1999.

[34] Munir F, Yarker J, Haslam C, et al. Work factors related to psychological and health-related distress among employees with chronic illnesses. J Occup Rehab. 2007; 17: 259-77. 
[35] Health \& Safety Executive. Self-reported work-related illness and workplace injuries 2005/2006. Sudbury, Suffolk: HSE Books, 2007.

[36] Kuijer RG, DeRidder DTD. Discrepancy in illness-related goals and quality of life in chronically ill patients: the role of self-efficacy. Psychol Health. 2003;18: 313-30.

[37] Weijman I, Ros WJ, Rutten GEHM, Schaufeli WB, Schabracq MJ, Winnubst AM. The role of work-related and personal factors in diabetes selfmanagement. Patient Educ Couns. 2005; 59: 87-96.

[38] Lorig K, Stewart A, Ritter P, Gonzalez V, Laurent D, Lynch J. Outcome measures for Health Education and other Health Care Interventions. Sage, Thousand Oaks, 1996.

[39] Clark NM, Dodge JA. Exploring self-efficacy as a predictor of disease management. Health Educ Behav. 1999; 26: 72-89.

[40] Munnell A, Libby J. Will people be healthy enough to work longer? Center for Retirement Research, Boston. 2007; 3: 1-11.

[41] Eriksen W, Sandvik L, Bruusgaard D. Does dietary supplementation of cod liver oil mitigate musculoskeletal pain? Eur J Clin Nutr. 1996; 689-93. 
[42] Rennie J. Body maintenance and repair: how food and exercise keep the musculoskeletal system in good shape. Exp Phys. 2005; 427-36.

[43] Houston DK, Stevens J, Cai JW, Haines PS. Dairy, furit, and vergetable intakes and functional limitations and disability in a biracial cohort: the Atherosclerosis Risk in Communities Study. Am J Clin Nutr. 2005; 515-22.

[44] Department of Health. Choosing a better diet: a food and health action plan. Department of Health. London, 2005.

[45] Department of Health. The musculoskeletal services framework. Department of Health. London, 2006.

[46] Lemon BW, Bengston VL, Peterson JA. An exploration of the activity theory of aging: activity types and life satisfaction among in-movers to a retirement community. J Gerontol. 1972; 27: 511-23.

[47] Campbell PG, MacAuley D, McCrum E, Evans A. Age differences in the motivating factors for exercise. J Sport Exerc Psychol. 2001; 23: 191-99.

[48] Harris AHS, Cronkite R, Moos R. Physical activity, exercise coping, and depression in a 10 year cohort study of depressed patients. J Affect Disord. 2006; 93: 79-85. 
[49] Strawbridge WJ, Deleger S., Roberts RE, Kaplan GA. Physical activity reduces the risk of subsequent depression for older adults. Am J Epidemiol. 2002; 156: 328-34.

[50] Department of Health. Choosing activity: a physical activity action plan. Department of Health. London, 2005.

[51] Taylor AH. Physical activity, anxiety and stress. In: Biddle SJH., Fox KR, Boutcher, SH, eds. Physical activity and psychology well-being. London: Routledge; 2000: 10-45.

[52] Cherkin DC, Sherman KJ, Deyo RA, Shekelle, PG. A review of the evidence for the effectiveness, safety, and cost of acupuncture, massage therapy, and spinal manipulation for back pain. Ann Intern Med. 2003; 138: 898-906.

[53] Trades Union Congress. Rehabilitation and retention: the workplace view. Labour Research Department: TUC; 2002.

[54] Mazzeo RS. Exercise and physical activity for older adults. Med Sci Sports Exerc. 1998; 30: 992-1008. 
Table 1: Descriptive statistics for chronic disease by age (younger and older workers) and gender

\begin{tabular}{|c|c|c|c|c|c|c|}
\hline \multirow[t]{2}{*}{ Type of illness } & \multicolumn{2}{|c|}{ Age } & \multirow[t]{2}{*}{$\chi^{2}$ value } & \multicolumn{2}{|c|}{ Gender } & \multirow[t]{2}{*}{$\chi^{2}$ value } \\
\hline & $\begin{array}{l}20-49 \\
\text { N }(\%)\end{array}$ & $\begin{array}{l}50-69 \\
\mathrm{~N} \quad \%)\end{array}$ & & $\begin{array}{l}\text { Male } \\
\mathrm{N}(\%)\end{array}$ & $\begin{array}{l}\text { Female } \\
\mathrm{N}(\%)\end{array}$ & \\
\hline Musculoskeletal pain & $150(66.4)$ & $76(33.6)$ & $8.46 * *$ & $111(49.1)$ & $115(50.8)$ & 1.33 \\
\hline Arthritis \& rheumatism & $60(47.1)$ & $70(53.8)$ & $21.94 * *$ & $43(34.1)$ & $87(65.9)$ & $7.80 * *$ \\
\hline Asthma & $87(68.7)$ & $39(31.0)$ & $16.20 *$ & $61(48.1)$ & $65(51.9)$ & 0.39 \\
\hline Depression \& anxiety & $81 \quad(68.7)$ & $37(31.4)$ & $6.26 * *$ & $54(44.6)$ & $64(55.4)$ & 0.04 \\
\hline Heart disease & $33(41.8)$ & $46(58.2)$ & $12.13 * *$ & $57(72.5)$ & $22(27.5)$ & $25.33^{* *}$ \\
\hline Diabetes & $39(48.8)$ & $41(51.3)$ & 5.67 & $46(57.5)$ & $34(42.5)$ & $5.01 * *$ \\
\hline$\chi^{2}$ value & $84.75^{* *}$ & $32.41 * *$ & & $48.24 * *$ & $90.09^{* * *}$ & \\
\hline
\end{tabular}

Note: Significant: $* \mathrm{p}<.05, * * \mathrm{p}<.01$ 
Table 2: Percentage of participants advised to carry out a health behaviour at home and at work

\begin{tabular}{|c|c|c|c|c|c|c|c|c|c|c|c|c|c|c|c|c|}
\hline \multirow{2}{*}{ Type of illness } & \multicolumn{4}{|c|}{ Medication } & \multicolumn{4}{|c|}{ Diet } & \multicolumn{4}{|c|}{ Symptoms } & \multicolumn{4}{|c|}{ Exercise } \\
\hline & $\begin{array}{l}\text { Hon } \\
\mathrm{N}\end{array}$ & ne & $\begin{array}{l}\text { Wor } \\
\mathrm{N}\end{array}$ & & $\begin{array}{l}\text { Hom } \\
\mathrm{N}\end{array}$ & $\%$ & $\begin{array}{l}\text { Wor } \\
\mathrm{N}\end{array}$ & & $\begin{array}{l}\text { Hom } \\
\mathrm{N}\end{array}$ & $\%$ & $\begin{array}{l}\text { Wor } \\
\mathrm{N}\end{array}$ & & $\begin{array}{l}\text { Hon } \\
\mathrm{N}\end{array}$ & $\%$ & $\begin{array}{l}\text { Wor } \\
\mathrm{N}\end{array}$ & $\%$ \\
\hline Musculoskeletal pain & 160 & 70.8 & 189 & 83.6 & 127 & 56.2 & 124 & 54.8 & 207 & 91.5 & 205 & 90.7 & 201 & 88.9 & 195 & 86.3 \\
\hline Asthma & 106 & 84.1 & 105 & 83.3 & 92 & 73.0 & 92 & 73.0 & 107 & 84.9 & 115 & 91 & 103 & 81.7 & 101 & 80.2 \\
\hline Depression \& anxiety & 96 & 81.3 & 93 & 78.8 & 70 & 59.3 & 69 & 58.5 & 105 & 90.0 & 100 & 84.7 & 92 & 78.0 & 79 & 70.0 \\
\hline Heart disease & 76 & 96.2 & 78 & 98.7 & 72 & 91.1 & 67 & 84.8 & 77 & 97.4 & 71 & 89.8 & 72 & 91.2 & 66 & 83.5 \\
\hline
\end{tabular}


Table 3: Mean difference in health behaviours carried out by younger and older workers

\begin{tabular}{lccccc}
\hline Work $\begin{array}{l}\text { Younger } \\
\text { behaviour }\end{array}$ & Mean & SD & Mean & SD & t-test \\
\cline { 2 - 5 } Medication & 7.88 & 2.483 & 8.27 & 2.330 & $-2.531^{*}$ \\
Diet & 6.13 & 2.937 & 6.99 & 2.618 & $-4.208^{* *}$ \\
Symptoms & 6.45 & 2.953 & 6.87 & 2.971 & $-2.263^{*}$ \\
Exercise & 4.69 & 3.025 & 5.34 & 3.086 & $-3.196^{* *}$ \\
\hline
\end{tabular}

Note: Significant: ${ }^{*} p<.05,{ }^{* *} p<.01$. 
Table 4: Standardised regression estimates for young and older workers in health behaviours associated with chronic disease management in the workplace

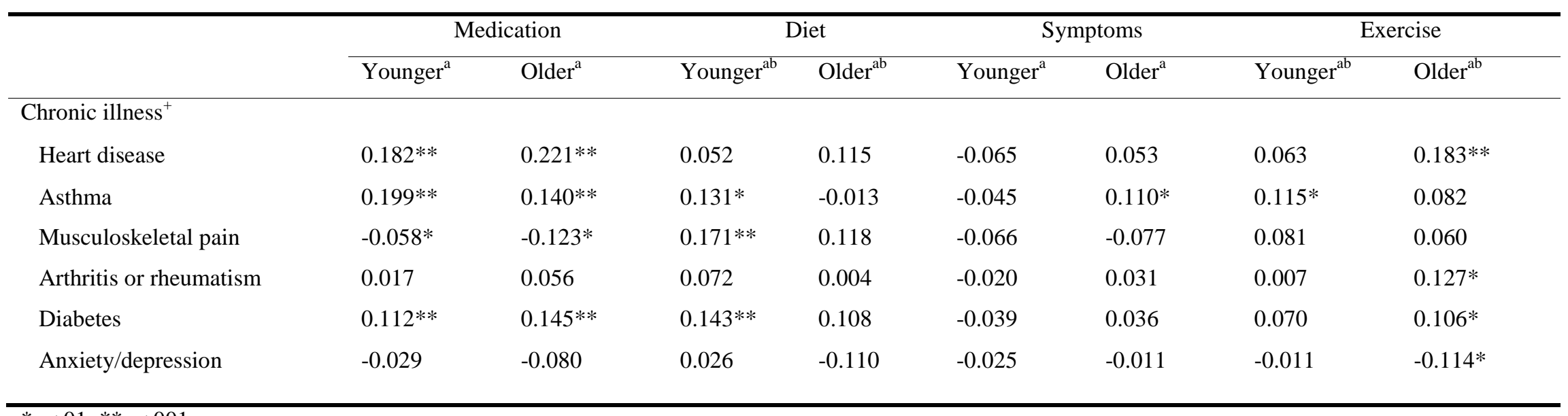

$* \mathrm{p}<.01, * * \mathrm{p}<.001$

${ }^{+}$Each chronic disease group was treated as a separate dummy variable with each chronic disease group contrasted against all other groups

${ }^{a}$ Multiple linear regression model adjusted for organization, tenure, occupation $(1=$ manual, 2 = non-manual) gender (dummy coded $1=$ male;

$2=$ female), illness severity, time since diagnosis

${ }^{\mathrm{b}}$ Additionally adjusted for BMI (body mass index $\left(\mathrm{kg} / \mathrm{m}^{2}\right)$ 
